\title{
Consistency and sensitivity of stream periphyton community structural and functional responses to nutrient enrichment
}

\author{
Craig E. Nelson, ${ }^{1,3}$ Danuta M. Bennett, ${ }^{1}$ and Bradley J. Cardinale ${ }^{2}$ \\ ${ }^{1}$ Marine Science Institute, University of California, Santa Barbara, California 93106 USA \\ ${ }^{2}$ School of Natural Resources and Environment, University of Michigan, Ann Arbor, Michigan 48109 USA
}

\begin{abstract}
Eutrophication remains one of the foremost impacts of industrialization and population expansion on aquatic ecosystems worldwide. Selecting metrics for assessing the manner in which communities and biogeochemical processes respond to nutrient fertilization is an ongoing management challenge critical both for detecting changes and for monitoring recovery of impaired environments. A key limitation to the selection of response variables is the lack of consistent evaluation of metrics under the same conditions in multiple systems across ecoregions. Here we report the results of nutrient-diffusing agar fertilization experiments conducted simultaneously in 30 streams in two distinct ecoregions of California, USA: the mountainous Sierra Nevada and the coastal chaparral of Santa Barbara county. In each experiment we evaluated algal community shifts across five nutrient delivery rates using multiple response variables at the ecosystem process (respiration and primary production), community (biomass and diversity metrics), functional group (nitrogen fixing, growth form, nutrient adaptation), and taxonomic group (indicator species, genera, families) levels of ecological organization. We used mixed-effect general linear models to quantify the magnitude, sensitivity, and consistency of responses among streams within and across ecoregions to provide an objective assessment of the potential for each variable to describe and detect significant changes in algal community characteristics. Our results indicate that ecosystem- and community-level variables showed significant and consistent nutrient responses among diverse streams and across the two ecoregions, while indicator taxa and functional groups were less likely to respond consistently to nutrient enrichment. We discuss the relevance of our findings to the ongoing development of monitoring and bioassessment strategies for aquatic eutrophication.
\end{abstract}

Key words: algae; assessment; biodiversity; colonist; ecosystem function; indicator; mixed models; nutrient diffusing substrata; Santa Ynez, California, USA; Sierra Nevada, California, USA.

\section{INTRODUCTION}

Eutrophication, high productivity driven by the excessive input of nutrients to ecosystems, is one of the most prominent forms of environmental change in the modern era (Bartsch 1970, Vitousek et al. 1997, Carpenter et al. 1998, Smith et al. 1999). Over the past century, humans have nearly doubled the rate of nitrogen inputs into terrestrial ecosystems and ambient phosphorus concentrations have increased by $75 \%$ or more (Vitousek et al. 1997, Bennett et al. 2001, Canfield et al. 2010). Excessive nutrient loading now ranks among the leading causes of biodiversity loss (Suding et al. 2005) and is the primary contributor to water pollution (Carpenter et al. 1998, Dodds 2006) and hypoxia in freshwater and marine habitats worldwide (Diaz and Rosenberg 2008). While legislation in developed countries has led to far better controls on point sources of nutrient pollution during the past 40

Manuscript received 20 February 2012; revised 5 July 2012; accepted 10 July 2012; Corresponding Editor (ad hoc): W. K. Dodds.

${ }^{3}$ E-mail: craig.nelson@lifesci.ucsb.edu years, nonpoint sources have continued to rise, exacerbating the environmental impacts (Bennett et al. 2001). Given the global ecological and economic impact of these environmental problems (Dodds et al. 2008), a primary goal of modern environmental policy is to both predict and mitigate the excessive input of nutrient into ecosystems (Smith and Schindler 2009).

Over the past 3-4 decades, a large amount of research has been dedicated to identifying which ecological variables can best predict the onset of, or recovery from, excessive nutrient loading. Much of this research can be broadly categorized into three general approaches. The first approach has attempted to identify individual species that are sufficiently widespread and sensitive enough to nutrient inputs that changes in their individual fitness, density, or geographic distribution might serve as a biological indicator of nutrient pollution (Dufrêne and Legendre 1997, Simberloff 1998, Caro and O’Doherty 1999, Potapova and Charles 2007, Fleishman and Murphy 2009). Second, an equally large body of work has attempted to aggregate species into higher taxonomic groups (genera, families, etc.) or into functional groups that share certain biological traits 
(body size classes, growth forms, etc.), in order to determine which groupings show the most consistent responses to nutrient loading (Grime 1977, Steneck and Dethier 1994, Suding et al. 2005). One final avenue of research has focused on how the properties of a whole community (e.g., species richness, community biomass, etc.) or ecosystem-level processes performed by those communities (e.g., ecosystem metabolism, nutrient cycling) respond to nutrient inputs (Cottingham and Carpenter 1998, Dodds 2006). While each of these approaches has had some success, none have provided wholly satisfying predictions for the ecological impacts of nutrient fertilization. Because of this, there has been ongoing debate about which metrics and levels of ecological organization (populations, communities, or ecosystems) most strongly and consistently reflect the impacts of excessive nutrient loading (Vitousek et al. 1997, Simberloff 1998, Dodds and Welch 2000).

Here we present the results of a comparative study in which we used a standardized assay to perform nutrient fertilization experiments simultaneously in 30 streams that were located in two distinct geographic regions of California, USA. We then assessed the significance, strength, and consistency of responses by stream periphyton biofilms to nutrient additions using a suite of taxonomic, functional, community, and ecosystem-level metrics. Specifically, we used nutrientdiffusing agar substrates to enrich local patches in a stream with nitrate and phosphate and then examined how fertilization influenced (1) rates of primary production (gross [GPP] and net [NPP]) and community respiration by stream biofilms (which included both algae and heterotrophic organisms), (2) the total biomass, taxonomic diversity, and taxonomic composition of algal periphyton, and (3) the density of individual species of algae or of species joined into larger taxonomic groups (e.g., genera, families) or functional groups based on shared biological characteristics. With these data, we asked two questions: (1) Which variables respond significantly and consistently to nutrient augmentation across streams and geographic regions and (2) which variables have the strongest response to fertilization and highest variance explained? Our study offers a rare comparison of how a suite of ecological variables responds to nutrient enrichment across streams that vary in their species pools and abiotic characteristics.

\section{Materials And Methods}

\section{Study sites}

During the summer of 2006, we conducted identical nutrient augmentation experiments in 30 streams that were located in two distinct ecoregions of California. Twenty streams were located in the eastern Sierra Nevada within the Mono, East Walker, and Crowley watersheds (labeled as M, EW, and C in Fig. 1; see Plate 1). This portion of the Sierra Nevada range (EPA Type III ecoregion 5) is characterized by a terrain that was strongly glaciated, is underlain by granite, and dominated by lodgepole pine, as well as fir and spruce at higher elevations. The other 10 streams were located in the coastal watersheds that flow from the Santa Ynez mountains of southern California into the Santa Barbara channel (labeled as SY and SB in Fig. 1). This area (EPA Type III ecoregion 6) is characterized by a mediterranean climate of hot, dry summers and cool, moist winters, and associated vegetative cover of chaparral and oak woodlands. We chose these two ecoregions primarily because of the history of research that has occurred in each region. In the Sierra Nevadas, we have completed a sequence of studies that have examined algal responses to nutrient loading (Cardinale et al. 2009). In the Santa Ynez, the University of California-Santa Barbara runs a Long Term Ecological Research (LTER) program with historical records on the physical, chemical, and biological characteristics of the streams. Thus, both regions have good historical information on stream nutrient levels and species composition, and this project was intended to augment ongoing work. Locations of the streams and detailed information on their physical and chemical properties are given in the complete data set (see Supplement).

Within each of these two ecoregions, we selected stream sites based on three constraints. First, it was necessary to choose streams that were located on private land for which we had permission to work or that were located in secure and remote locations so that experiments could run undisturbed by anglers or hikers during the roughly two-month duration of the nutrient incubations. This criterion precluded any type of random selection of streams. We have no reason to believe that the subset of streams ultimately selected for our study represents any type of biased subset, and we believe them to be representative of streams for each ecoregion as a whole. Second, with the aid of prior surveys and species lists (Blinn and Herbst 2003, Herbst and Blinn 2007), we chose streams that represented a variety of different periphyton assemblages (differing levels of richness and varying types of dominant species) so that we could assess the consistency of responses to nutrients for different ecological communities. Third, we chose streams that spanned a representative range of ambient nutrient levels within each ecoregion so that we could assess the consistency of responses under contrasting nutrient regimes (see Appendix A for a figure that summarizes the range of ambient nutrient characteristics of the chosen streams). In the Sierra Nevada concentrations of nitrate ranged from 1.04 to 14.98 $\mu \mathrm{mol} / \mathrm{L}$ with a lognormal median of 8.11 and concentrations of phosphate ranged from 0.03 to $12.82 \mu \mathrm{mol} / \mathrm{L}$ with a lognormal median of 1.89 . In the Santa Ynez concentrations of nitrate ranged from 0.74 to 1263 $\mu \mathrm{mol} / \mathrm{L}$ with a lognormal median of 52.5 and concentrations of phosphate ranged from 0.027 to $3.2 \mu \mathrm{mol} / \mathrm{L}$ with a lognormal median of 0.08 . 

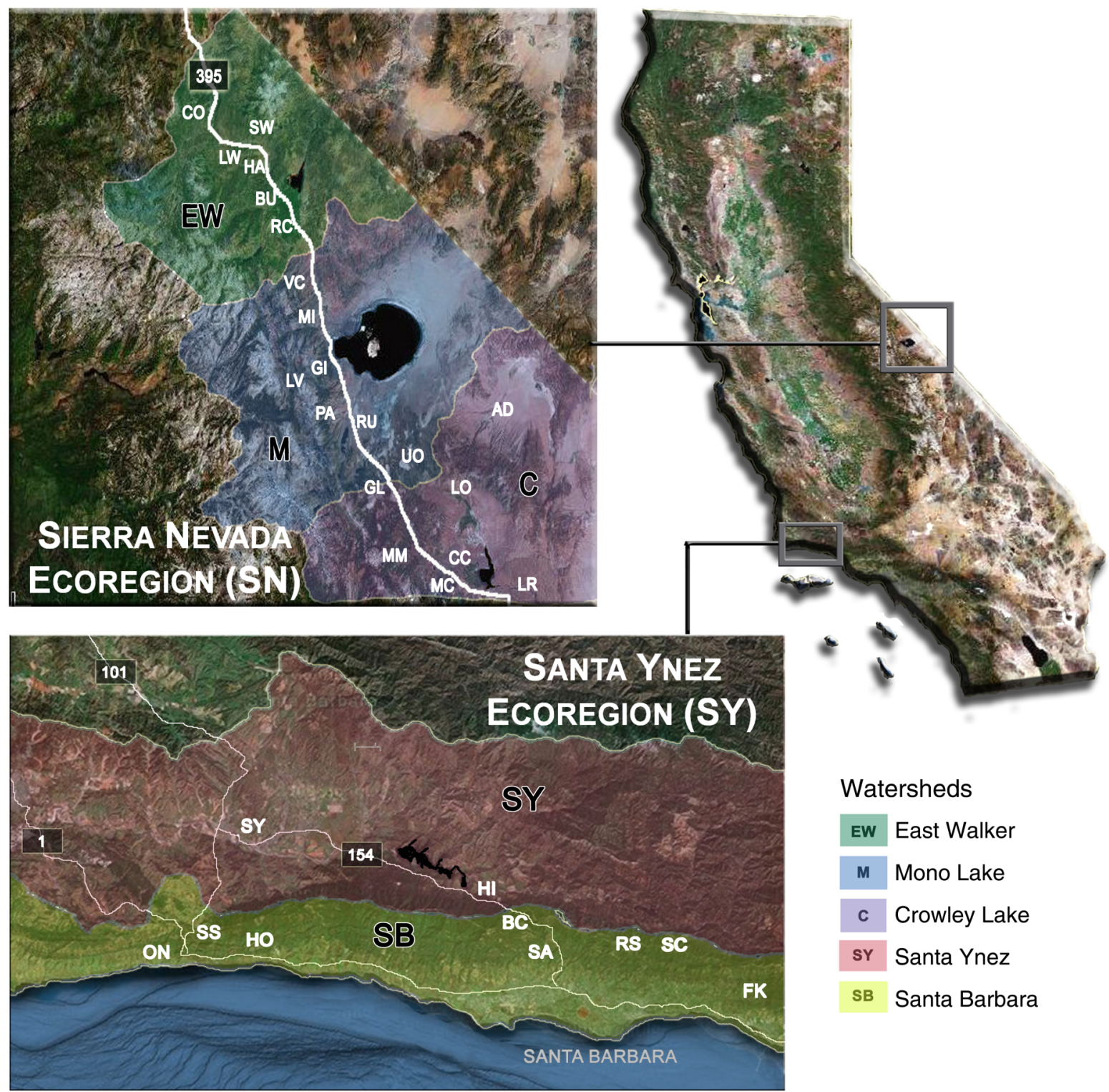

Watersheds

\begin{tabular}{|c|l|}
\hline Ew & East Walker \\
\hline M & Mono Lake \\
\hline C & Crowley Lake \\
\hline sY & Santa Ynez \\
\hline SB & Santa Barbara \\
\hline
\end{tabular}

FIG. 1. Location of the study sites. Study streams are annotated with two-letter codes among watersheds located in the Owens River and Mono Lake basin of the Eastern Sierra Nevada mountain range (region SN) and streams in watersheds around Santa Barbara (region SY), California, USA. Abbreviations correspond to the complete data set provided in the Supplement.

\section{Nutrient augmentations}

Nutrient manipulations were conducted in each of the 30 streams using nutrient-diffusing substrata (NDS), which have been widely used as a standard assay for comparing the response of periphyton to nutrient additions across streams (Pringle and Bowers 1984, Fairchild et al. 1985, Francoeur 2001, Tank and Dodds 2003). Pictures and full details of the agar-filled NDS used in this study have been previously reported in Cardinale et al. (2009) and are reproduced here in Appendix A: Fig. A2. Briefly, each NDS was composed of five L-shaped 500-mL polyvinylchloride (PVC) tubes that were embedded in a $42 \mathrm{~cm}$ wide $\times 42 \mathrm{~cm}$ long $\times 8$ cm deep concrete block that was sufficiently heavy to keep the substrate flush with the bottom of streambed sediments in moderately high flows. Each L-shaped tube ended in a $12.56-\mathrm{cm}^{2}$ opening on the surface of the concrete block, which was the only exposed agar surface that allowed for periphyton growth. Each of the Lshaped PVC tubes on an NDS was randomly assigned to one of five nutrient treatments: no-nutrient controls (tube filled with 2\% agar only) or four levels of $\mathrm{N}$ and $\mathrm{P}$ amended to the agar at a constant 16:1 molar ratio $\left(\mathrm{NaNO}_{3} / \mathrm{K}_{2} \mathrm{HPO}_{4}\right.$ added to the $2 \%$ agar at concentrations of $1.0 \times 10^{-6} / 6.25 \times 10^{-8}, 1.0 \times 10^{-4} / 6.25 \times 10^{-6}$, $1.0 \times 10^{-2} / 6.25 \times 10^{-4}$, or $\left.1.0 / 6.25 \times 10^{-2} \mathrm{~mol} / \mathrm{L}\right)$. These 
levels of agar concentrations yield nutrient diffusion delivery rates that range from ambient nutrient concentrations in each stream (controls) to one order of magnitude higher than what has been observed in either of the two regions (Lewis et al. 1999, Sickman et al. 2002; see also Appendix A: Fig. A3). We chose to vary N and $\mathrm{P}$ in concert for two reasons. First, our goal in this experiment was to mimic the process of cultural eutrophication, which generally increases the availability of both $\mathrm{N}$ and $\mathrm{P}$ in most ecosystems (Ryther and Dunstan 1971, Howarth et al. 1996, Vitousek et al. 1997, Carpenter et al. 1998, Dodds 2006). Second, recent summaries of nutrient addition experiments suggest that algal communities most often exhibit joint responses to $\mathrm{N}$ and $\mathrm{P}$ and that single nutrient additions frequently underestimate the community-level response to fertilization (Francoeur 2001, Elser et al. 2007).

The NDS were deployed from 17 to 22 July 2006 (SY region) and from 24 to 28 July 2006 (SN region) and remained in the streams for $42 \pm 1 \mathrm{~d}$ (mean $\pm \mathrm{SD}$; range 39-43 d) during a period of summer base flows (no major rain events or marked increases in discharge). Nutrient release rates measured on cores taken from the NDS at the end of the 42-d incubation period spanned almost an order of magnitude and were directly proportional to initial nutrient concentrations (Appendix A: Fig. A3).

\section{Community metabolism}

At the end of the 42-d experiment, we used light/dark incubations to measure changes in dissolved oxygen (DO) to estimate rates of net biofilm production (for ease of interpretation labeled NPP, although heterotrophs do exist within the biofilms) and respiration $(R)$ (Odum 1956, Marzolf et al. 1994). The NDS were briefly removed from the stream so that $4.0 \mathrm{~cm}$ diameter $\times 12.5$ $\mathrm{cm}$ deep acrylic tubes fitted with a DC motor and stirring propeller could be sealed with vacuum grease to form an airtight chamber on the outside of each agar patch. Chambers were then filled with stream water that had been filtered through a $40-\mu \mathrm{m}$ mesh. The entire substrate with metabolism chambers was placed in a water bath in an open-canopy area on the stream bank where water was constantly replaced with stream water using hand pumps so that incubations were performed at ambient stream temperature (deviation from initial stream temperature $0.5^{\circ} \pm 1.0^{\circ} \mathrm{C}$ ). Biofilm community respiration on the nutrient patch $(R)$ was measured as the amount of DO consumed during a 1-h incubation (using YSI model 556 probes; Yellow Springs, Ohio, USA) with water baths covered with a black tarp that precluded any exposure to light (which was verified using a handheld light meter). Net biofilm production (NPP) was then measured as the change in $\mathrm{O}_{2}$ during subsequent $1-\mathrm{h}$ incubations in ambient sunlight. Gross primary production (GPP) was calculated as the sum of $R$ and NPP. While all metabolic measurements were intentionally conducted on cloudless days under ambi- ent sunlight, we did measure photosynthetically active radiation (PAR) using a handheld light meter to account for potential variation in light levels among sampling dates. We describe how we handled this potential covariate statistically later in Statistical analyses.

\section{Algal biomass and species identifications}

To characterize the composition and richness of potential algal colonist species in each stream, we selected an arbitrary but consistent number $(N=10)$ of median-sized rocks $\left(d_{50} \sim 50 \mathrm{~mm}\right)$ from a minimum of two riffles upstream of our experimental site and removed periphyton from a $12.56-\mathrm{cm}^{2}$ surface area on each rock using a knife and/or toothbrush, pooling samples into a composite that was preserved in $2 \%$ formalin for algal identifications and enumeration. Periphyton samples were then collected from each nutrient-diffusing agar by removing the top 1-mm layer of agar with a razor knife. This layer was divided into two subsamples, the first preserved in $2 \%$ formalin as above for algal identifications and enumeration. The second subsample was preserved in a $15-\mathrm{mL}$ low-density polyethylene conical centrifuge tube with $10 \mathrm{~mL}$ of $90 \%$ $\mathrm{EtOH}$, which was then transported to the laboratory on ice, frozen $\left(-20^{\circ} \mathrm{C}\right)$ to lyse algal cells for $7-28 \mathrm{~d}$, then analyzed spectrophotometrically (trichromatic method with acidification, DU 800 Spectrophotometer; Beckman Coulter, Brea, California, USA) to quantify the amount of chlorophyll $a$ as a measure of algal biomass (Steinman and Lamberti 1996). Samples for algal identifications and enumeration were examined at $1000 \times$ magnification using oil immersion on an Olympus BX50 microscope (Olympus America, Center Valley, Pennsylvania, USA) under bright field illumination. Species richness in each sample was estimated by scanning slides systematically until no new taxon was found in 10 subsequent transects (i.e., until a species sampling curve was confirmed to reach saturation). Taxa were identified to the lowest taxonomic unit possible during enumeration (usually species). Algal identifications were made from preserved specimens. In rare cases in which there was any doubt about species assignment ( $<10$ of 493 species), taxa were assigned to a genus and differentiated as morphospecies. Species abundances were calculated by enumerating all live cells (with an intact chloroplast) from a known volume (minimum 300 cells on each slide) and then calculating areal estimates of density. Total algal biovolume, a second measure of algal biomass, was estimated by measuring the cell dimensions of $\sim 10$ individuals from each species and fitting these to known geometric shapes (Hillebrand et al. 1999). Biovolumes were summed across all individuals and species in a sample to obtain a community-level biovolume.

\section{Algal functional and taxonomic groups}

Algal species were classified according to the June 2009 versions of the Integrated Taxonomic Information 
System (available online) ${ }^{4}$ and AlgaeBase (available online). ${ }^{5}$ Taxonomic groupings were generated at all higher levels of organization (genus, family, etc.) using these identifications and were analyzed for nutrient response in absolute densities. Each of the 493 species that were identified during our experiments was assigned to functional groupings based on similarities in life history traits or previously documented associations with nutrient concentrations (summarized in Appendix B). These functional groupings included growth morphology (unicellular, filamentous, or colonial), cell size (nano-, micro-, or macro-algae; 2-20 $\mu \mathrm{m}, 20-200 \mu \mathrm{m}$, and $>200 \mu \mathrm{m}$ diameters, respectively; Dussart 1965), and ability to fix nitrogen (DeYoe et al. 1992). Diatoms were further grouped according to their potential to be indicators of high or low $\mathrm{N}$ or $\mathrm{P}$ based on prior studies that have detailed North American species distributions along gradients in total phosphorus (TP) and nitrogen (TN) (Potapova and Charles 2007). Species that did not clearly fit into any particular group were assigned the status of "unknown" in each category, and these were excluded from analysis for that particular functional classification.

\section{Environmental covariates}

At the beginning and end of each experiment, we measured ambient levels of light (Apogee Quantum light meter; Apogee Instruments, Logan, Utah, USA), canopy cover above the streambank (handheld densitometer; Forestry Suppliers, Jackson, Missouri, USA), flow (Sontek Acoustic Doppler velocimeter; Sontek, San Diego, California, USA), and stream width (tape measure) as these parameters have a high likelihood of covarying with the response variables in which we were interested (see Cardinale et al. 2009). Because the response of algae to nutrient enrichment is known to depend on ambient nutrient concentrations (Welch et al. 1988, Dodds et al. 2002), we also measured ambient stream dissolved inorganic nutrient concentrations at the end of each experiment by collecting water samples and filtering them through Whatman $\mathrm{GF} / \mathrm{F}$ filters (nominal pore size $0.7 \mu \mathrm{m}$ ). These samples were frozen and later analyzed for concentrations of ammonium, nitrate (including nitrite), and orthophosphate on a flow injection autoanalyzer (Quickchem 8000; Lachat Instruments, Loveland, Colorado, USA) at the University of California at Santa Barbara Marine Science Institute Analytical Laboratory. Because ambient ammonium levels were consistently below limits of detection, we calculated stream ambient nutrient ratios using only the ratio of nitrate to orthophosphate.

\section{Statistical analyses}

We used mixed-effect general linear models (GLMs) to analyze the relationship between agar nutrient

\footnotetext{
${ }^{4}$ http://www.itis.gov/index.html

${ }^{5} \mathrm{http}: / /$ www.algaebase.org
}

concentrations and the suite of individual response variables considered across all streams and both ecoregions. The suite of ecosystem, community, and functional response variables are summarized in Table 1, and the longer list of taxonomic response variables are provided in Appendix C. Our models were constructed identically to those reported by Cardinale et al. (2009) except that ecoregion (SY or SN) was included as a fixed effect to test for regional variation in responses. In addition, an interaction term between nutrient concentration and ecoregion was included to test for regional variation in the slope of nutrient responses. Thus, all models took the general form $y_{i j}=\mu+\beta_{1}\left[\log _{10}\right.$ nutrient concentration $]_{i j}+\beta_{2}[\text { ecoregion }]_{i j}+\beta_{3}$ [ecoregion $\times$ $\log _{10}$ nutrient concentration] $+b_{i}+\varepsilon_{i j}$, where $y_{i j}$ is the dependent variable for experimental unit $j$ from stream $i$, $\beta$ are the parameter estimates associated with each independent variable, $b_{i}$ is the random effect associated with different stream sites $i$, and $\varepsilon_{i j}$ is the residual error. If nutrient concentration was significant in the full model (reported as $P_{\mathrm{Nu}}<0.05$ ) and the nutrient $\times$ ecoregion interaction was not significant $\left(P_{\mathrm{Nu} \times \mathrm{Rg}}>\right.$ 0.05 ), we considered the response to be consistent across ecoregions. Whenever this was the case, only the singular mixed-model parameters are reported. If the interaction term was significant $\left(P_{\mathrm{Nu} \times \mathrm{Rg}}<0.05\right)$ then results for separate models in each ecoregion were summarized (SN and SY); if neither term was significant $\left(P_{\mathrm{Nu}}>0.05\right.$ and $\left.P_{\mathrm{Nu} \times \mathrm{Rg}}>0.05\right)$ then this indicates no response to nutrient augmentation.

There are two modifications of the GLM analyses described above that warrant mention. First, because species richness proved to be a concave-down function of nutrient enrichment and did not fit a linear model, we modified the GLM for this particular variable to have a quadratic term. In doing so, we followed the approach of Cardinale et al. (2009) who both standardized and centered species richness at zero to minimize covariance between the linear and quadradic terms, thus providing better estimates of the curvilinearity. We only analyzed density responses with mixed models for taxonomic or functional group populations that we deemed sufficiently widespread (defined as those found on $\geq 50 \%$ of the NDS agars in both ecoregions); for taxa that did not meet this criterion, we felt that data were insufficient to generate robust statistical models.

The elevated probability of making Type I errors when multiple tests are run (as in the case of testing hundreds of taxa for responses to nutrients) increases the likelihood that the few taxa that are identified as exhibiting statistically significant responses to nutrients are erroneously identified. Controlling the family-wide error rate with a correction to alpha (e.g., Bonferroni) or controlling the false discovery rate (FDR) using a method such as that recommended by Storey and Tibshirani (2003), which we have applied in similar studies testing many taxa (e.g., Huang et al. 2011), would have minimized this possibility. However, these 
TABLE 1. Summary of response of periphyton to nutrient enrichment among streams and ecoregions.

\begin{tabular}{|c|c|c|c|c|c|c|c|c|}
\hline \multirow[b]{2}{*}{ Response variable } & \multirow[b]{2}{*}{ Units } & \multicolumn{5}{|c|}{ Full model } & \multicolumn{2}{|c|}{ Full model with N:P } \\
\hline & & $P_{\mathrm{Nu}}$ & $r^{2}$ & Intercept & Slope & $P_{\mathrm{Nu} \times \mathrm{Rg}}$ & $P_{\mathrm{Nu}}$ & $P_{\mathrm{Nu} \times \mathrm{Rg}}$ \\
\hline \multicolumn{9}{|l|}{ Ecosystem } \\
\hline Gross primary production & $\mathrm{mg} \mathrm{O}_{2} \cdot \mathrm{cm}^{-2} \cdot \mathrm{h}^{-1}$ & 0.098 & 0.74 & 0.026 & 0.001 & 0.401 & 0.040 & 0.731 \\
\hline Net primary production & $\mathrm{mg} \mathrm{O} \mathrm{O}_{2} \cdot \mathrm{cm}^{-2} \cdot \mathrm{h}^{-1}$ & 0.057 & 0.72 & 0.004 & 0.000 & 0.660 & 0.014 & 0.851 \\
\hline Respiration & $\mathrm{mg} \mathrm{O} \mathrm{O}_{2} \cdot \mathrm{cm}^{-2} \cdot \mathrm{h}^{-1}$ & 0.704 & 0.94 & 0.021 & 0.000 & 0.566 & 0.524 & 0.781 \\
\hline Production : respiration & unitless ratio & 0.044 & 0.51 & 1.348 & 0.033 & 0.316 & 0.031 & 0.515 \\
\hline \multicolumn{9}{|l|}{ Community } \\
\hline Chlorophyll $a$ & $\log _{10}\left(\mu \mathrm{g} \mathrm{chl} a / \mathrm{cm}^{2}\right)$ & 0.003 & 0.45 & -0.639 & 0.056 & 0.048 & 0.003 & 0.065 \\
\hline Biovolume & $\ln \left(\mu \mathrm{m}^{3} / \mathrm{cm}^{2}\right)$ & 0.661 & 0.48 & 19.497 & -0.016 & 0.007 & 0.484 & 0.127 \\
\hline Species richness (quadratic) & agar: colonists & 0.005 & 0.38 & 0.398 & -0.007 & 0.536 & 0.006 & 0.639 \\
\hline Species evenness & Simpson's index & 0.027 & 0.27 & 0.419 & -0.010 & 0.129 & 0.015 & 0.240 \\
\hline \multicolumn{9}{|l|}{ Functional group } \\
\hline \multicolumn{9}{|l|}{ Diatom nutrients } \\
\hline Low-N taxa & no. cells $/ \mathrm{cm}^{2}$ & 0.000 & 0.68 & 9.399 & -0.167 & 0.083 & 0.007 & 0.522 \\
\hline Low-P taxa & no. cells $/ \mathrm{cm}^{2}$ & 0.046 & 0.73 & 9.190 & -0.082 & 0.092 & 0.050 & 0.106 \\
\hline High-N taxa & no. cells $/ \mathrm{cm}^{2}$ & 0.474 & 0.58 & 11.594 & -0.031 & 0.022 & 0.859 & 0.086 \\
\hline High-P taxa & no. cells $/ \mathrm{cm}^{2}$ & 0.677 & 0.59 & 11.658 & 0.018 & 0.134 & 0.788 & 0.104 \\
\hline \multicolumn{9}{|l|}{ N-fixers } \\
\hline $\mathrm{N}$-fixing taxa & no. cells $/ \mathrm{cm}^{2}$ & 0.256 & 0.51 & 8.935 & -0.069 & 0.054 & 0.887 & 0.340 \\
\hline Non-N-fixing taxa & no. cells $/ \mathrm{cm}^{2}$ & 0.889 & 0.34 & 13.044 & -0.005 & 0.009 & 0.579 & 0.066 \\
\hline \multicolumn{9}{|l|}{ Cell size } \\
\hline Medium (micro) & no. cells $/ \mathrm{cm}^{2}$ & 0.232 & 0.53 & 12.346 & -0.040 & 0.011 & 0.689 & 0.084 \\
\hline Small (nano) & no. cells $/ \mathrm{cm}^{2}$ & 0.902 & 0.48 & 11.224 & -0.006 & 0.004 & 0.725 & 0.003 \\
\hline \multicolumn{9}{|l|}{ Cell growth form } \\
\hline Unicellular & no. cells $/ \mathrm{cm}^{2}$ & 0.550 & 0.35 & 12.892 & -0.021 & 0.007 & 0.698 & 0.088 \\
\hline Colonial & no. cells $/ \mathrm{cm}^{2}$ & 0.888 & 0.46 & 9.214 & -0.008 & 0.075 & 0.840 & 0.180 \\
\hline Filamentous & no. cells $/ \mathrm{cm}^{2}$ & 0.978 & 0.48 & 10.041 & -0.001 & 0.038 & 0.756 & 0.108 \\
\hline
\end{tabular}

Notes: Response variables are organized according to hierarchical levels of ecological organization. General linear model (GLM) parameters $\left(P, r^{2}, n\right.$, slopes, and intercepts) are listed for the full model as well as a subsequent model including ambient stream nutrient ratios as a covariate; additional GLM parameters are listed separately by system in Appendix C when the response to nutrients differed by system $\left(P_{\mathrm{Nu} \times \mathrm{S}}<0.05\right)$. Values in boldface indicate significance at $\alpha=0.05$. Taxonomic group responses and additional information on sample sizes and species per population are listed in Appendix C.

types of corrections were inappropriate for this data set because we are explicitly comparing the consistency of responses across multiple ecological levels (each of which have different numbers of tests) and we ultimately feel that the need to control Type I errors is less critical than maintaining a standardized statistical comparison across metrics.

Many environmental parameters other than simply nutrient enrichment (e.g., light, cover, flow, width, and ambient nutrients) have the potential to influence the response variables measured in this study. It would be impractical, if not impossible, to statistically control for all of these potential covariates in any one analysis, as the amount of data required to do so would be orders of magnitude greater than the 30 streams included in our study. We instead ran additional GLM models that examined each environmental variable separately as a fixed covariate to determine which, if any, had potential to alter our conclusions. We then summarized statistically significant differences in the models and their effects on the interpretations of the results where necessary.

The goal of the GLMs described here was to examine the significance and consistency of responses across streams and geographic regions. While these broader analyses allow us to describe the "general" trends across streams, they ignore the variation that occurs within streams. Therefore, we complemented our construction of GLMs with a second set of analyses in which we examined the strength of response by each variable within individual streams, as well as the consistency in response within streams. To do this, we used linear regressions to quantify the slopes and coefficients of determination ( $r^{2}$ values) describing the response of each variable to nutrient fertilization in each of the 30 streams. We then examined the frequency distributions of relative change (slope:intercept) to assess the strength of response and used a Wilcoxon signed-ranks test to determine whether mean relative change differed from zero. We relativized the slopes to each stream intercept in order to have an unbiased metric comparable among streams and ecosystems with widely varying levels of response variables in the ambient environment. We similarly examined the frequency distribution of $r^{2}$ values to assess the consistency of each response variable within individual streams. Lastly, to test whether algal species composition differed among streams, treatments, and ecoregions, we calculated Sorensen distances 

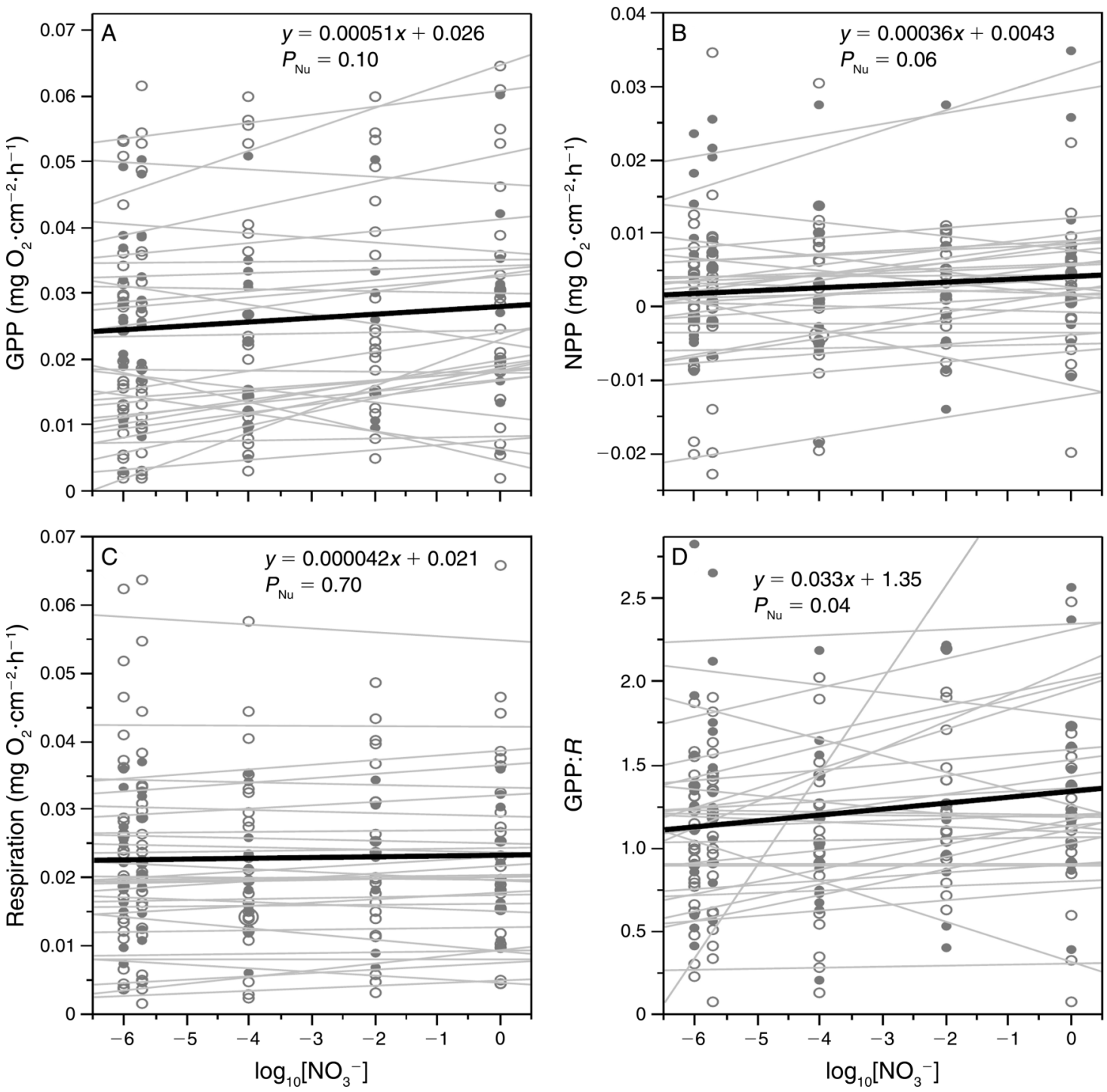

FIG. 2. Responses of ecosystem-level variables to nutrient enrichment across all streams. Relationships between (A) gross primary production (GPP), (B) net primary production (NPP), (C) respiration ( $R$ ), and (D) GPP : $R$ as a function of enrichment rate of nutrients. Nutrient concentrations are reported as initial nutrient-diffusing substrata (NDS) concentration of molar nitrate (with orthophosphate amended also at constant 16:1 N:P ratio); log-transformed values were originally measured in mol/L. Gray lines represent the regressions for each of the 30 streams; each symbol represents a single observation. The heavy black line and equations in each plot give the best fit from a mixed-effects general linear model that uses maximum likelihood to estimate parameter values after accounting for the random variation among streams. Solid circles represent ecoregion SY, and open circles represent ecoregion SN (see Fig. 1 for locations).

between samples from cell abundance data (aka BrayCurtis dissimilarity); statistical tests of a priori group differentiation (multiple response permutation procedure [MRPP]) were done in PC-ORD version 5 (McCune and Mefford 1999).

\section{RESULTS}

Question 1: Which variables respond significantly and consistently to nutrient fertilization?

Biofilm metabolism.- Rates of gross primary production (GPP) within the biofilms spanned more than an order of magnitude $\left(0.0018-0.073 \mathrm{mg} \mathrm{O} \mathrm{O}_{2} \cdot \mathrm{cm}^{-2} \cdot \mathrm{h}^{-1}\right)$. Background levels of GPP varied widely among streams (note variation in intercepts in Fig. 2A), and responses of GPP to nutrient augmentation ranged from positive to negative in individual streams (note variation in the slopes for individual streams, gray lines). After accounting for random variation in the responses among streams, results of a mixed-model ANOVA suggested that mean levels of GPP did not vary as a function of nutrient enrichment $\left(P_{\mathrm{Nu}}=0.10\right.$; dark solid line in Fig. 2A; Table 1). There was also no evidence that the 

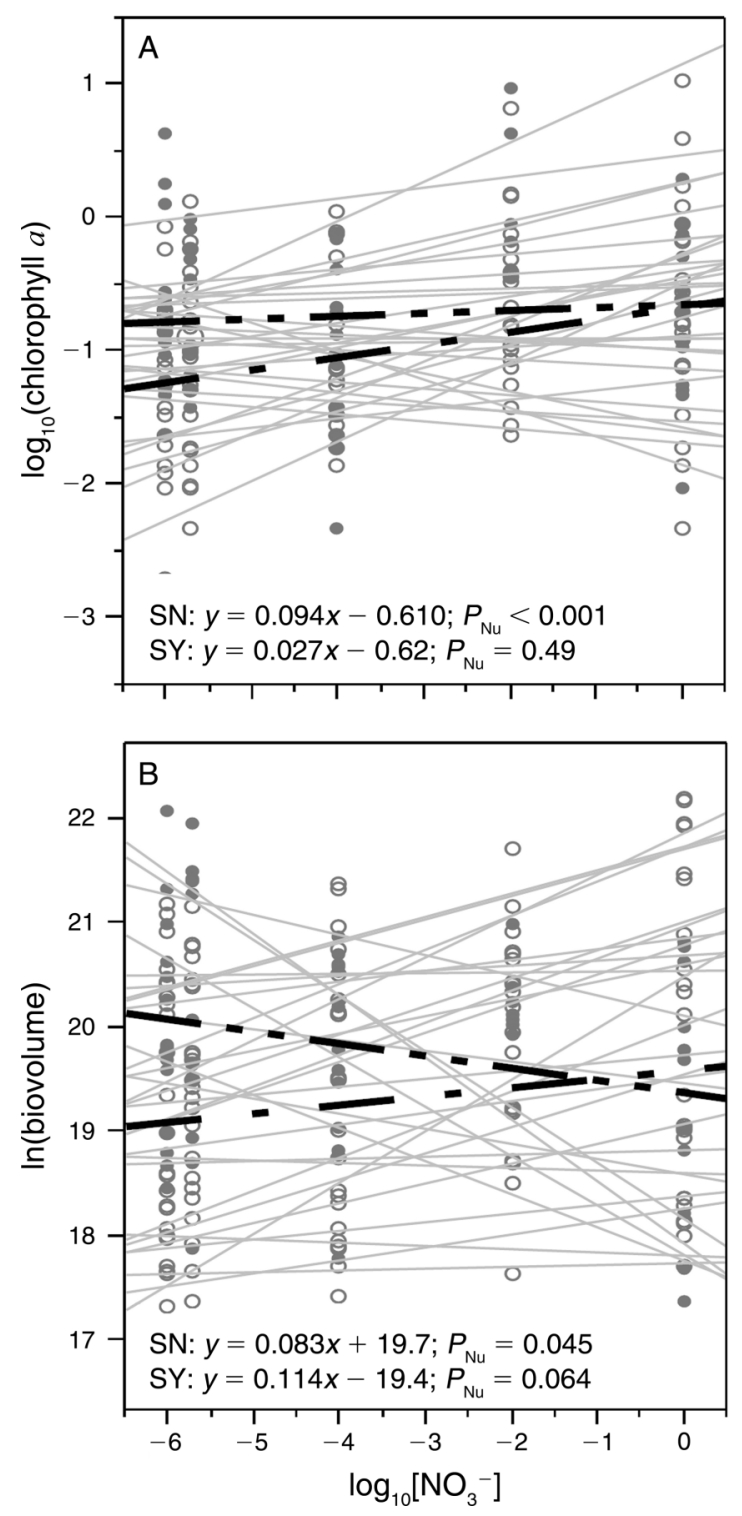

FIG. 3. Algal biomass relationships to nutrient enrichments across streams and among regions. Original units are: chlorophyll $a, \mu \mathrm{m} / \mathrm{cm}^{2}$; biovolume, $\mu \mathrm{m}^{3} / \mathrm{cm}^{2}$; nutrient concentration, mol/L. Because mixed models indicated a significant interaction term (ecoregion $\times$ nutrient), separate models are fit and reported in the figure for each ecoregion, with the doubledashed lines representing ecoregion SY and the single-dashed lines representing ecoregion SN (see Fig. 1 for locations). Other details are as in Fig. 2.

response of GPP to nutrient augmentation differed among ecoregions, as evidenced by the lack of a nutrient $\times$ ecoregion interaction $\left(P_{\mathrm{Nu} \times \mathrm{Rg}}=0.40\right.$; Table 1$)$. Rates of net primary production (NPP) increased by a mean $3.6 \times 10^{-4} \mu \mathrm{g} \mathrm{O}_{2} \cdot \mathrm{cm}^{-2} \cdot \mathrm{h}^{-1}$ for each $\log _{10}$ increase in nutrient enrichment $\left(P_{\mathrm{Nu}}=0.06\right.$; Fig. 2B, Table 1), with the response being consistent among ecoregions $\left(P_{\mathrm{Nu} \times \mathrm{Rg}}\right.$ $=0.66$; Table 1). Biofilm respiration $(R)$ showed no significant response to nutrient enrichment in either ecoregion (Table 1, Fig. 2C). When GPP was standardized relative to $R$ (GPP: $R$ ) to give an index of metabolic balance, values ranged from 0.07 (indicating net heterotrophic activity) to 5.05 (indicating net autotrophic activity) with median values of 1.17 in both ecoregions. The ratio GPP: $R$ increased significantly with nutrient augmentation $\left(P_{\mathrm{Nu}}=0.04\right.$; Fig. 2D, Table $1)$, and the response was consistent among ecoregions $\left(P_{\mathrm{Nu} \times \mathrm{Rg}}=0.32\right.$; Table 1$)$. When background nutrient concentrations were included as covariates, the response of all ecosystem productivity parameters (NPP, GPP, and GPP : $R$ ) to nutrient augmentation strengthened in significance or transitioned from being marginally significant to having $P_{\mathrm{Nu}}<0.05$ (Table 1), while respiration response was unaffected by the addition of background nutrients as a covariate (Table 1).

Algal biomass.-Background levels of chlorophyll a spanned almost three orders of magnitude among the streams (see intercepts in Fig. 3A; note $\log _{10}$ scale). The amount of chlorophyll $a$ increased with nutrient augmentation in the Sierra Nevada streams $\left(P_{\mathrm{NuSN}}<\right.$ 0.01 , slope 0.083 ; Fig. 3A), but did not vary with nutrient enrichment in SY streams $\left(P_{\mathrm{NuSN}}=0.49\right)$. A second metric of algal biomass, community biovolume, also tended to increase with nutrient enrichment in $\mathrm{SN}$ streams $\left(P_{\mathrm{NuSN}}=0.04\right.$, slope 0.075 ; Fig. 3B $)$, but showed a marginally significant negative response in SY streams $\left(P_{\text {NuSY }}=0.06\right.$, slope -0.114 ; Fig. $\left.3 \mathrm{~B}\right)$. Thus, the response of algal community biomass to nutrient enrichment was not consistent among ecoregions. In addition, trends for the two most commonly used metrics of algal biomass (chlorophyll $a$ and community biovolume) were not necessarily consistent with one another. When stream ambient nutrient concentrations were included as a covariate in models, chlorophyll $a$ remained statistically significant with respect to nutrient augmentation and both chlorophyll and biovolume no longer exhibited variation among regions $\left(P_{\mathrm{Nu} \times \mathrm{Rg}}>\right.$ 0.05; Table 1).

Algal richness and evenness. - We identified between 33 and 139 species of algae on natural substrata in the streams, which we refer to as the "colonist pool." We found a general concave-down relationship between nutrient concentration and the proportion of species from the colonist pool that were found on individual agars $\left(P_{\mathrm{Nu}}<0.01\right.$ for centered polynomial term $\log [\mathrm{N}]^{2}$; Table 1, Fig. 4A). This relationship was consistent among the two ecoregions $\left(P_{\mathrm{Nu} \times \mathrm{Rg}}=0.54\right.$, Table 1$)$. The second aspect of diversity, species evenness, declined as nutrient concentration increased $\left(P_{\mathrm{Nu}}=0.03\right.$; Table 1 , Fig. 4B), and this decline was consistent in both ecoregions $\left(P_{\mathrm{Nu} \times \mathrm{Rg}}=0.13\right.$; Table 1$)$. When ambient nutrient concentrations were included as a covariate, both richness and evenness remained significant $\left(P_{\mathrm{Nu}}<\right.$ 0.03; Table 1).

Algal functional groups.-Diatom species that have previously been grouped according to their distribution in streams characterized by low nitrogen and phospho- 

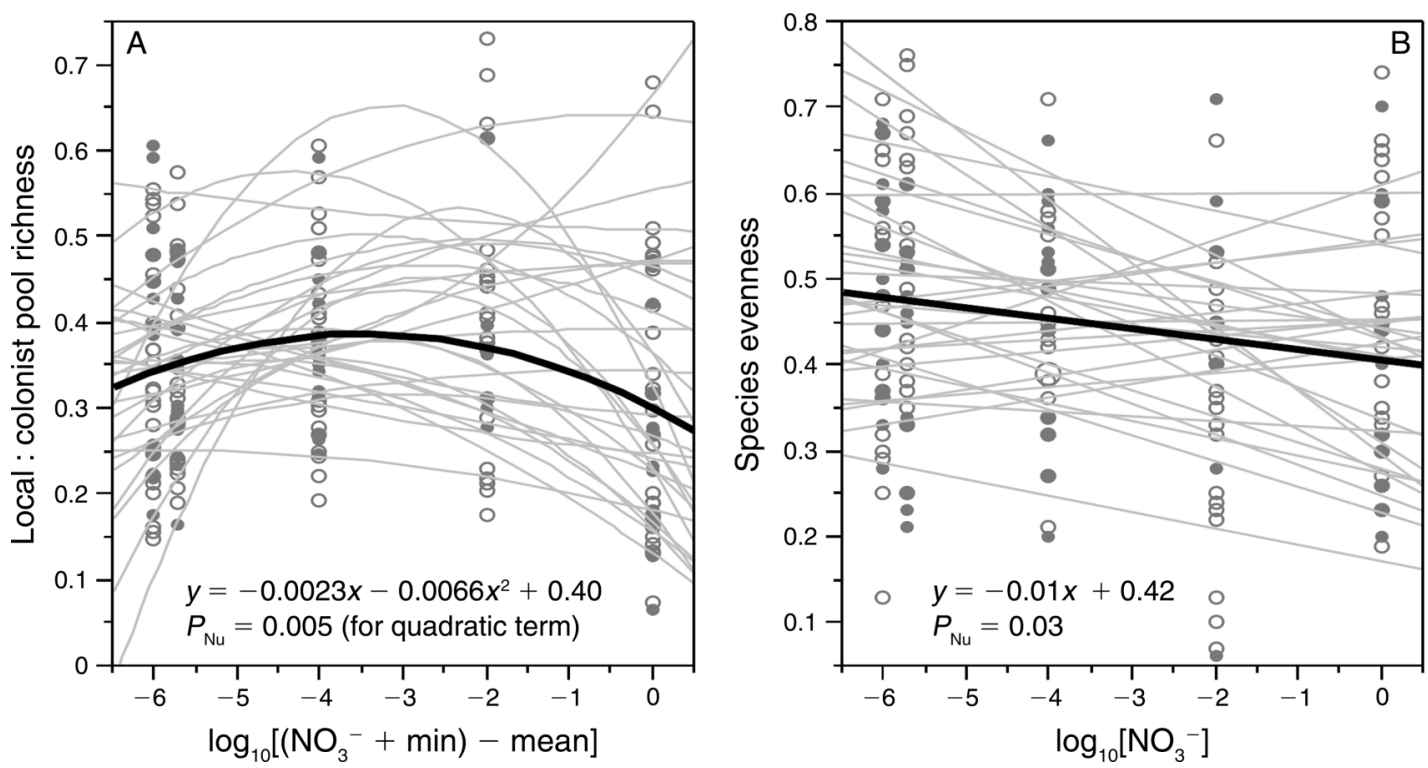

FIG. 4. Response of community-level variables to nutrient enrichment across all streams. (A) Response of algal species richness (local: colonist richness is the richness on experimental agar relative to algal colonist pool species in streams) found at the end of the experiment as a function of centered nutrient enrichment rate, $\log _{10}$ (nutrient + minimum $)-$ mean, originally measured as mol/L. (B) Shannon evenness response to increasing nutrient enrichment rate, $\log _{10}$ (nutrient), originally measured as mol/L. Details are as for Fig. 2.

rus $(\mathrm{TN}<200 \mu \mathrm{g} / \mathrm{L}$ and/or $\mathrm{TP}<10 \mu \mathrm{g} / \mathrm{L}$; Potapova and Charles 2007) showed a decrease in population density as nutrient enrichment increased $\left(P_{\mathrm{Nu}}<0.01\right.$ and $P_{\mathrm{Nu}}=0.05$, respectively; Table 1$)$. These responses were consistent across ecoregions. In contrast, diatom taxa that have previously been associated with high $\mathrm{N}$ or $\mathrm{P}$ did not show a consistent response to nutrients either within or across regions $\left(P_{\mathrm{Nu}}>0.47\right.$; Table 1$)$.

Functional groups based on algal cell size showed variable responses to nutrient enrichment among ecoregions $\left(P_{\mathrm{Nu} \times \mathrm{Rg}} \leq 0.01\right.$; Table 1$)$. Density of nano-sized algae increased with nutrient enrichment in the Sierra Nevada streams $\left(P_{\mathrm{NuSN}}=0.02\right)$ but declined in the Santa Ynez $\left(P_{\mathrm{NuSY}}=0.04\right)$. Density of micro-sized algae similarly decreased with nutrient enrichment in the Santa Ynez streams $\left(P_{\mathrm{NuSY}}=0.05\right)$ but did not respond to nutrients in the Sierra Nevadas $\left(P_{\mathrm{NuSN}}=0.21\right)$. Functional groupings of algae defined by cellular growth form did not exhibit any significant response to nutrient augmentation in either ecoregion (Table 1). Lownutrient indicator diatom groupings maintained a significant response to nutrient enrichment after inclusion of ambient inorganic N:P as a covariate $\left(P_{\mathrm{Nu}}<\right.$ 0.05), but other functional groups showed no significant response to nutrient enrichment (either within or between systems) when $\mathrm{N}: \mathrm{P}$ ratio was included as a covariate $\left(P_{\mathrm{Nu}}>0.05\right.$ and $P_{\mathrm{Nu} \times \mathrm{Rg}}>0.05$; Table 1$)$.

Algal taxonomic groups. - We identified a sum total 493 species from the 30 streams. Of these, $87 \%$ were diatoms (Bacillariophyta). Multivariate community analysis indicated that species found on natural substrates and on nutrient agars grouped distinctly by stream (MRPP $A=0.21, P<0.001)$ and by ecoregion (MRPP $A=0.03, P<0.001$ ). In contrast, there was no consistent grouping associated with a particular nutrient enrichment (our agar treatments) across streams or among regions (MRPP $P>0.6$ ). As a result, our treatments of nutrient enrichment explained almost no variation in the composition of species among streams. Instead, nearly all of the variation in species composition was due to streams and ecoregions having unique species pools.

Because nutrient enrichment explained little variation in species composition, few species found on the nutrient agars were sufficiently cosmopolitan (i.e., found in at least half of the samples from each region) to evaluate their response to fertilization (analyses could be run on just 33 species). Changes in cell densities with nutrient enrichment were either nonsignificant or inconsistent among regions for 31 of these 33 species (Appendix C). Only two species showed a consistent response among streams and ecoregions. The density of Epithemia sorex consistently decreased with nutrient augmentation $\left(P_{\mathrm{Nu}}\right.$ $=0.04$, Appendix C), whereas the density of Cylindrospermum spp. consistently increased $\left(P_{\mathrm{Nu}}=0.05\right.$; Appendix C). As noted in Materials and methods, the elevated probability of making Type I errors when multiple tests are run (as in the case of testing hundreds of taxa for responses to nutrients) increases the probability that the sole two species that showed statistically significant responses to nutrients actually did not show significant responses because their $P$ values are very near our alpha threshold of 0.05 . 


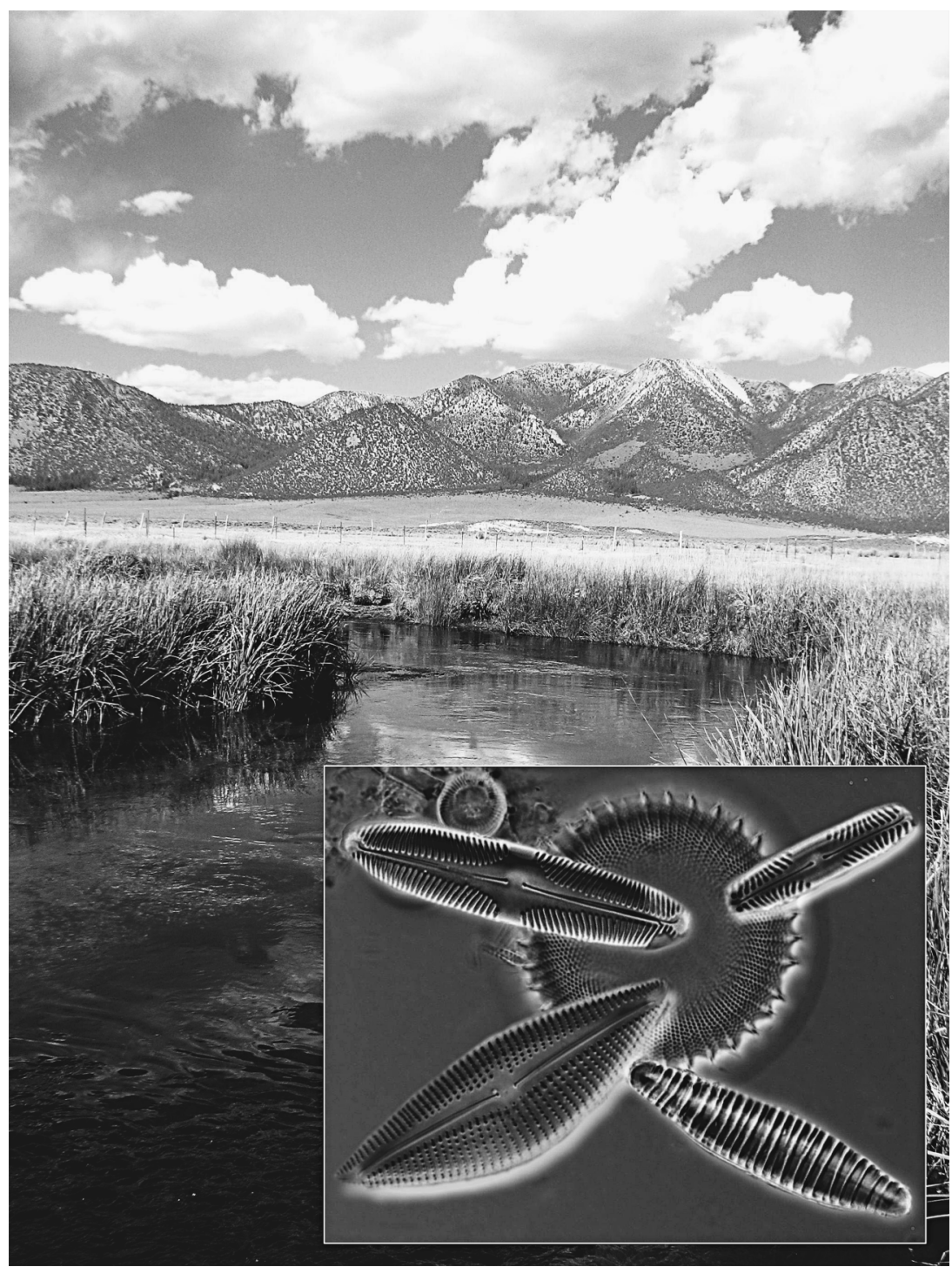

Plate 1. A stream sampled in this study in the Long Valley Caldera of the eastern Sierra Nevada (USA). This reach is lower Mammoth Creek (just above the confluence with Hot Creek), with the Glass Mountains in the background. The inset shows a microscopic overlay of four representative diatom genera from samples collected in the Sierra Nevada for this study: two Pinnularia and one each Cymbella, Diatoma, and Stephanodiscus. Photo credits: D. M. Bennett.

When we organized species into higher taxonomic levels, we similarly found a relatively small number of consistent responses to nutrient augmentation. Of the three dominant phyla (Bacilliarophyta, Chlorophyta, and Cyanobacteria), none showed any consistent response to nutrient augmentation (Appendix C). Only two of six classes of algae (Coscinodiscophyceae and Fragilariophyceae), five of 16 orders, and five of 22 families showed a consistent response to nutrient augmentation $\left(P_{\mathrm{Nu}}<0.05\right.$; Appendix $\left.\mathrm{C}\right)$, but the direction of these responses were varied. Of the genera identified, only three were found in $>50 \%$ of samples from each region: Cocconeis, Navicula, and Nitzschia. Of these, only Cocconeis showed a consistent response to nutrients in either region $\left(P_{\mathrm{Nu}}<0.05\right.$; Appendix $\left.\mathrm{C}\right)$. Taxonomic groups showed no significant response to nutrient enrichment (either within or between systems) when N:P ratio was included as a covariate $\left(P_{\mathrm{Nu}}>0.05\right.$ and $P_{\mathrm{Nu} \times \mathrm{Rg}}>0.05$; Table 1 ).

Statistical control for covariates. - In additional GLM models incorporating physical and chemical covariates, the only environmental factors that influenced model conclusions were those describing ambient stream nutrient concentrations as noted in respective sections above (Table 1, Appendix D; ambient concentrations of $\mathrm{N}$ and $\mathrm{P}$ and the nutrient ratio $\mathrm{N}: \mathrm{P}$ exhibited similar influence on model outcomes). When background nutrient concentrations were included as covariates, 
the response of all ecosystem productivity parameters (NPP, GPP, and GPP:R) to nutrient augmentation strengthened in significance or transitioned from being marginally significant to having $P_{\mathrm{Nu}}<0.05$; there was no effect on biofilm respiration significance. All community-level responses that had been significant (richness, evenness, and chlorophyll $a$ ) remained significant $\left(P_{\mathrm{Nu}}<0.03\right)$ and community-level responses that showed significant regional variation (biovolume and chlorophyll) no longer had a significant nutrient $\times$ region interaction term. With the exception of lownutrient indicator diatom groupings, which maintained a significant response to nutrient enrichment after inclusion of ambient inorganic $\mathrm{N}: \mathrm{P}$ as a covariate $\left(P_{\mathrm{Nu}}\right.$ $<0.05$ ), taxonomic and functional groups showed no significant response to nutrient enrichment (either within or between systems) when the $\mathrm{NO}_{3}{ }^{-}: \mathrm{PO}_{4}{ }^{3-}$ ratio was included as a covariate $\left(P_{\mathrm{Nu}}>0.05\right.$ and $\left.P_{\mathrm{Nu} \times \mathrm{Rg}}>0.05\right)$. Thus, accounting for the covariates that were available only served to strengthen our original conclusions.

Potential for nonlinear response.- It is possible that the structural and functional responses of periphyton communities to nutrient loading are nonlinear. Nonlinearities have the potential to lead us to incorrect conclusions if, for example, the functional relationship follows a second-order polynomial and is concave-down (as might be characteristic of nutrient inhibition at high levels). To address this possibility, we ran polynomial models (of the form $y=b_{0}+b_{1} x+b_{2} x^{2}+\lambda+\varepsilon$ where $x$ is the nutrient concentration, $\lambda$ is the random effect of stream, and $\varepsilon$ is the unexplained error and compared the significance of the second-order polynomial term $b_{2} x^{2}$ ) on all ecosystem-process and community-level variables (NPP, GPP, $R, \mathrm{P}: R$, evenness, richness, chlorophyll, biovolume) as well as the two functional groups that were significant in linear models (low $\mathrm{N}$ and $\mathrm{P}$ diatom indicator functional groups; Table 1). For all of these, the second-order term that indicates nonlinearity was nonsignificant $(P>0.2)$ with the exception of biovolume. Biovolume was not significant in linear models $(P$ $=0.66)$ and clearly had a significant concave-down polynomial $(P=0.023)$ that remained significant when $\mathrm{N}: \mathrm{P}$ was included $(P=0.048)$. Because chlorophyll concentrations did not follow a similar polynomial trend, this suggests that cell volume metrics and chlorophyll are not measuring the same properties.

Question 2: Which variables respond to nutrients most strongly, and do these have a high explanatory power?

To assess the relative strength of response by each variable in each stream we divided the slope that quantifies the response of each variable to nutrient augmentation by the intercept that gives ambient levels of each variable in the absence of any nutrient addition. This metric gives a relative change per unit nutrient enrichment that can be readily compared among variables and across streams (Fig. 5A). Rates of productivity increased with nutrient amendment (NPP by $10.8 \%$, GPP by $0.8 \%$, and GPP : $R$ by $1.2 \%$ on average), and all were significantly greater than zero $(P$ $<0.05)$. Chlorophyll concentrations increased by $6.24 \%$ and species evenness declined $5.1 \%$ on average with each log increase in nutrient enrichment. The mean change in respiration and the mean change in community biovolumes did not differ from zero (Wilcoxon signedranks test; $P>0.05)$. The only other variables with a mean relative change that was different from zero were the functional group of low-nitrogen indicator diatom taxa, which decreased in density by an average of $1.37 \%$ $(P=0.04)$, and the order Naviculales, which increased in density by an average of $1.35 \%(P<0.01)$.

To quantify the explanatory power of the response variables, we summarized the coefficients of determination $\left(r^{2}\right)$ showing how much variation was explained by the nutrient treatments within each stream. The distribution of $N=30$ coefficients is given for each variable in Fig. 5B. Most response variables had relatively low explanatory power, with median coefficients of determination that were $<0.35$. The only notable exceptions, with median coefficients that were $>0.45$, were a suite of functional and taxonomic variables that included the densities of unicellular algae, Bacillariophytes, microalgae, and taxa that do not fix nitrogen. Species richness also had relatively high median coefficients of determination $\left(r^{2}=0.57\right.$; note that these values are not directly comparable to the linear models because of their quadratic structure).

\section{DisCUSSION}

Given the widespread nature and economic significance of eutrophication, ecologists and ecosystem managers have increasingly worked to develop effective programs for rapid detection of the effects of nutrient fertilization, as well as monitoring schemes to document recovery once nutrient pollution is detected and curtailed (Smith and Schindler 2009). While it would be preferable to take a multivariate approach to detection and monitoring of excessive nutrient loading, the unfortunate reality is that we lack funding, time, and personnel to monitor a large number of ecological parameters in all systems of concern. Limited availability of resources is why ecologists have spent considerable time and energy searching for "ecological indicators," that is, the subset of variables that are best able to detect change in response to stressors such as nutrient enrichment (Niemi and McDonald 2004). The desirable characteristics of indicators are relatively easy to agree on: a good indicator will consistently detect change across time and space, be sufficiently sensitive that it can reliably signal a response when a perturbation has occurred, and have a high signal-to-noise ratio so that the response can be detected against the backdrop of natural variation (Kelly and Harwell 1990, Cairns et al. 1993, McCormick and Cairns 1994, Cottingham and Carpenter 1998). But which variables best meet these criteria is not always clear. 


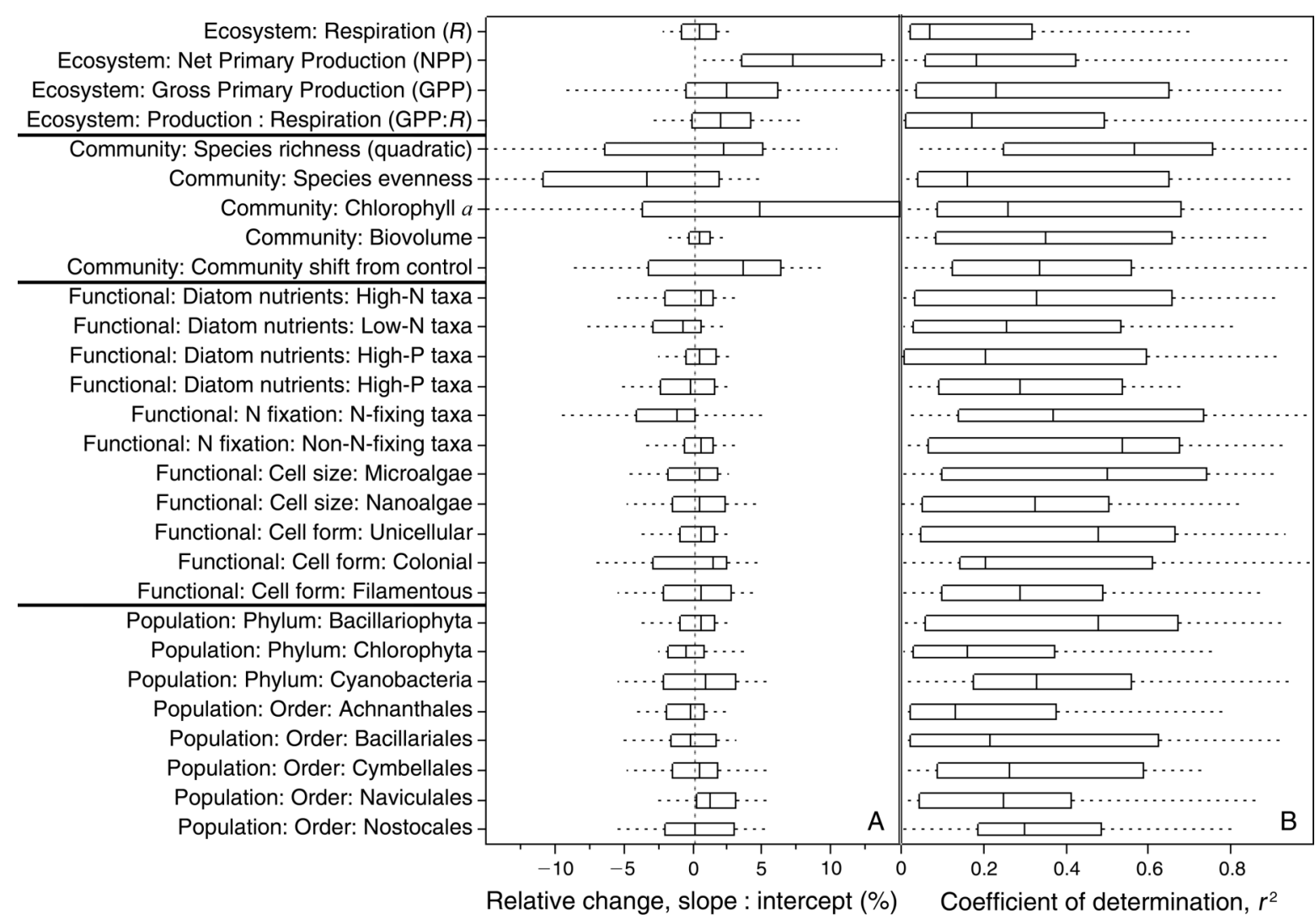

FIG. 5. Consistency and magnitude of individual stream models of ecosystem and community response to increasing nutrient delivery rates. Distributions of $(\mathrm{A})$ percentage change (slope : intercept) and (B) coefficients of determination $\left(r^{2}\right)$ for each response variable among 30 individual stream models. Boxes show median and $25 \%$ and $75 \%$ quantiles with whiskers extending to $90 \%$ quantiles.

To make choices more clear, it has been argued that we need more systematic evaluation of candidate indicators that are measured concurrently in the same system, under the same conditions, thus allowing for a direct comparison of their performance (Cottingham and Carpenter 1998). In this study, we used a standardized nutrient-diffusing assay to perform identical fertilization experiments in 30 streams spanning two geographic regions. We then used identical methods and analyses to quantify changes in (1) the density of individual species, (2) aggregated measures of populations into higher trophic or functional groups, (3) community properties like diversity and biomass, and (4) ecosystem-level processes such as metabolism. This allowed us to assess not only which variables show a significant response to fertilization, but which metrics exhibit the most consistent responses across streams and geographic regions and which have the strongest responses with the highest explanatory power.

When considering all criteria simultaneously (strength of response, consistency of response, and variation explained), several ecosystem process response variables measured in this study (net and gross primary production and GPP : $R$ ) ranked among the better indicators of fertilization. After statistically controlling for background nutrient concentrations in a stream, all of these variables showed a significant, positive response to nutrient enrichment (Table 1), with responses that were consistent across two ecoregions that differed considerably in algal species composition. The response of select variables (namely NPP) was also strong in magnitude within individual streams (Fig. 5A), even though measurements were characterized by high variability (Fig. 5B). However, the short duration ( 1 month) of our study, while longer than most experiments, may limit applicability of our conclusions to situations of acute nutrient stress, whereas streams with chronic nutrient stress may have the potential for alternate community adaption on longer timescales with different response profiles.

Responses of the ecosystem processes to nutrient loading in our study are qualitatively consistent with those of others who have looked at the impacts of nutrient loading on ecosystem-level processes. For example, Johnson et al. (2009) used diffusing substrates to measure the response of community respiration $(R)$ and gross primary production (GPP) to nutrient enrichment in 72 streams in the United States and 
Puerto Rico that were part of the Lotic Intersite Nitrogen Experiment II (LINXII). While the levels of metabolism measured in their study were an order of magnitude higher than those measured in ours, the authors found high consistent responses of $R$ across nearly all ecoregions and responses of GPP across half (Johnson et al. 2009: Fig. 3). The authors concluded that measures of biofilm metabolism were generally a sensitive indicator of water nutrient concentrations.

Community-level properties showed highly mixed success in our study. Chlorophyll $a$, perhaps the most widely used measure of algal biomass (Wetzel and Likens 2000), showed a consistent positive response to nutrient enrichment after background levels of nutrients were controlled for statistically (Table 1). Community biovolumes, a more labor-intensive and presumably more accurate estimate of biomass (Hillebrand et al. 1999), showed a qualitatively different response to fertilization in the two ecoregions and no response after controlling for ambient nutrient levels (Table 1). Species richness showed a general unimodal response to nutrient enrichment (the commonly documented hump-shaped curve; e.g., Waide et al. 1999, Cardinale et al. 2009). Evenness consistently declined with enrichment (Table 1), and the response was strong in individual streams (Fig. 5A). For many years, it has been argued that a reduction in biological diversity should be one of the most sensitive and early warning signs of an ecosystem's response to stress (Odum 1985, Rapport et al. 1985), and our results generally support this idea. Even so, we are broadly skeptical that species richness can be a useful indicator of nutrient enrichment anytime it follows a polynomial function since, by definition, this implies that even the qualitative response $(+, 0,-)$ depends on the level of enrichment. On the other hand, increased dominance and reduction in species evenness appear to be very general responses to fertilization that have been observed in a number of ecosystems (Hillebrand et al. 2007).

In contrast to community and ecosystem-level measures, the densities of individual species were generally poor indicators of fertilization response. Of the 493 species of algae identified in this study, only a small fraction (33) were sufficiently widespread that we could examine the generality of responses to fertilization across streams. Of these, only two taxa showed any consistent response to enrichment across ecoregions (Appendix C). Our inability to identify much consistency in the species-level information contrasts with work that has led to useful management tools based on indicator taxa (Pan et al. 1996, Menetrey et al. 2005, Potapova and Charles 2007, Donohue et al. 2009). Clearly, the limitation to using species-level data in our study was the high turnover of taxa among streams, and the restriction of our study to just two ecoregions hampers our ability to conjecture on whether this high turnover is a common feature of regional analyses. For streams in the Sierra Nevada ecoregion, we have previously shown that the vast majority of variation in algal community composition is explained by differences among streams, which have a mean Sorensen dissimilarity index of 0.90 (i.e., each stream's species pool was somewhat unique; Cardinale et al. 2009). While development of indicator taxa has been advocated in regionalized efforts to monitor water quality (Potapova and Charles 2007), high variation in the presence/ absence of species across geographic locations is a known impediment to using population-level responses as ecological indicators (McCormick and Cairns 1994, Cottingham and Carpenter 1998).

Aggregating species into functional groupings produced just one clear response to fertilization: when diatom species were grouped according to previous classifications that have associated species with low vs. high levels of TN and TP in U.S. streams (Potapova and Charles 2007), we found that density of the groups associated with low nutrient levels did, in fact, consistently decline as a function of fertilization (Table 1). On the other hand, diatoms that have previously been associated with high $\mathrm{N}$ or $\mathrm{P}$ did not show any consistent response to nutrient enrichment (Table 1), which emphasizes that these classifications were not entirely predictive of responses to nutrients in the areas where this study was performed. Aggregating species populations into higher taxonomic groupings produced little additional insight. None of the phyla revealed any consistent response to fertilization. When species were organized into classes, orders, or families, a relatively small number of groupings led to significant responses that were consistent across ecoregions (Appendix C). Of these, only one was robust across the taxonomic hierarchy (Fragilariophyceae). As such, we had very limited success in consistently documenting a response to fertilization using approaches that aggregate species populations into higher taxonomic groups or into previously used functional classifications.

Certain conclusions from our study appear to contrast with a common, qualitative view of aquatic ecosystems that suggests species population sizes will be very sensitive to ecosystem stress, whereas community and ecosystem-level properties will be "buffered" against change by the redundancy and compensatory responses among species (Odum 1985, Schindler 1990, Frost et al. 1995). In contrast, we would generally rank the ability of the different metrics measured in this study to quantify responses to fertilization as ecosystem $>$ community $>$ taxonomic $=$ functional metrics. Of course, this ranking is a crude generality that ignores many details and much variation in the responses of different variables. It is worth noting that there was no single measurement that showed a response to nutrients consistently across all streams, and no single variable simultaneously maximized all desirable properties of a good indicator. As such, there was no "silver bullet" for detecting ecological changes driven by fertilization. 
Even so, it is clear that certain types of measurements were more sensitive and reliable than others. Whether or not our results and conclusions generally apply to streams in other regions is uncertain, and our study spanned only two ecoregions, making the assessment of consistency across ecoregion limited in scope. But the value of our study is that it offers a rare opportunity to gauge the performance of different metrics under comparable conditions.

\section{ACKNOWLEDGMENTS}

C. E. Nelson and D. M. Bennett contributed equally to this work. Thanks to the Arcularius Ranch for granting access to the Upper Owens River via their property and to Kenny Eaton for access to Swauger Creek. Funding for this project was provided by NSF grants to B. J. Cardinale (DEB 0842009) and C. E. Nelson (DEB 0709975) with supplemental support from the Santa Barbara Channel LTER (OCE 0620276).

\section{Literature Cited}

Bartsch, A. F. 1970. Accelerated eutrophication of lakes in the United States: ecological response to human activities. Environmental Pollution 1970 1:133-140.

Bennett, E. M., S. R. Carpenter, and N. F. Caraco. 2001. Human impact on erodable phosphorus and eutrophication: a global perspective. BioScience 51:227-234.

Blinn, D. W., and D. B. Herbst. 2003. Use of diatoms and soft algae as indicators of environmental determinanats in the Lahontan Basin, USA. Annual Report under Contract Agreement 70455801CT766. California State Water Resources Board, South Lake Tahoe, California, USA. www.swrcb. ca.gov/rwqcb6/water_issues/programs/swamp/docs/blinn_ herbst periphyto dec2003.pdf

Cairns, J., P. V. McCormick, and B. R. Niederlehner. 1993. A proposed framework for developing indicators of ecosystem health. Hydrobiologia 263:1-44.

Canfield, D. E., A. N. Glazer, and P. G. Falkowski. 2010. The evolution and future of earth's nitrogen cycle. Science 330:192-196.

Cardinale, B. J., D. M. Bennett, C. E. Nelson, and K. Gross. 2009. Does productivity drive diversity or vice versa? A test of the multivariate productivity-diversity hypothesis in streams. Ecology 90:1227-1241.

Caro, T. M., and G. O'Doherty. 1999. On the use of surrogate species in conservation biology. Conservation Biology 13:805-814.

Carpenter, S. R., N. F. Caraco, D. L. Correll, R. W. Howarth, A. N. Sharpley, and V. H. Smith. 1998. Nonpoint pollution of surface waters with phosphorus and nitrogen. Ecological Applications 8:559-568.

Cottingham, K. L., and S. R. Carpenter. 1998. Population, community, and ecosystem variates as ecological indicators: phytoplankton responses to whole-lake enrichment. Ecological Applications 8:508-530.

DeYoe, H. R., R. L. Lowe, and J. C. Marks. 1992. Effects of nitrogen and phosphorus on the endosymbiont load of Rhopalodia gibba and Epithemia turgida (Bacillariophyceae)1. Journal of Phycology 28:773-777.

Diaz, R. J., and R. Rosenberg. 2008. Spreading dead zones and consequences for marine ecosystems. Science 321:926-929.

Dodds, W. K. 2006. Eutrophication and trophic state in rivers and streams. Limnology and Oceanography 51:671-680.

Dodds, W. K., W. W. Bouska, J. L. Eitzmann, T. J. Pilger, K. L. Pitts, A. J. Riley, J. T. Schloesser, and D. J. Thornbrugh. 2008. Eutrophication of U.S. freshwaters: analysis of potential economic damages. Environmental Science and Technology 43:12-19.
Dodds, W. K., et al. 2002. N uptake as a function of concentration in streams. Journal of the North American Benthological Society 21:206-220.

Dodds, W. K. K., and E. B. Welch. 2000. Establishing nutrient criteria in streams. Journal of the North American Benthological Society 19:186-196.

Donohue, I., L. A. Donohue, B. Ní Ainín, and K. Irvine. 2009. Assessment of eutrophication pressure on lakes using littoral invertebrates. Hydrobiologia 633:105-122.

Dufrêne, M., and P. Legendre. 1997. Species assemblages and indicator species: the need for a flexible asymmetrical approach. Ecological Monographs 67:345-366.

Dussart, B. H. 1965. Les différentes catégories de plancton. Hydrobiologia 26:72-74.

Elser, J. J., M. E. S. Bracken, E. E. Cleland, D. S. Gruner, W. S. Harpole, H. Hillebrand, J. T. Ngai, E. W. Seabloom, J. B. Shurin, and J. E. Smith. 2007. Global analysis of nitrogen and phosphorus limitation of primary producers in freshwater, marine and terrestrial ecosystems. Ecology Letters 10:1135-1142.

Fairchild, G. W., R. L. Lowe, and W. B. Richardson. 1985. Algal periphyton growth on nutrient-diffusing substrates: an in situ bioassay. Ecology 66:465-472.

Fleishman, E., and D. D. Murphy. 2009. A realistic assessment of the indicator potential of butterflies and other charismatic taxonomic groups. Conservation Biology 23:1109-1116.

Francoeur, S. N. 2001. Meta-analysis of lotic nutrient amendment experiments: detecting and quantifying subtle responses. Journal of the North American Benthological Society 20:358-368.

Frost, T., S. Carpenter, A. Ives, and T. Kratz. 1995. Species compensation and complementarity in ecosystem function. Pages 224-239 in C. G. Jones and J. H. Lawton, editors. Linking species and ecosystems. Chapman and Hall, New York, New York, USA.

Grime, J. 1977. Evidence for the existence of three primary strategies in plants and its relevance to ecological and evolutionary theory. American Naturalist 111:1169-1194.

Herbst, D., and D. Blinn. 2007. Preliminary index of biological integrity (IBI) for periphyton in the Lahontan Region, eastern Sierra Nevada, California. USEPA, Mammoth Lakes, California, USA.

Hillebrand, H., C. Dürselen, D. Kirschtel, U. Pollingher, and T. Zohary. 1999. Biovolume calculation for pelagic and benthic microalgae. Journal of Phycology 35:403-424.

Hillebrand, H., D. S. Gruner, E. T. Borer, M. E. S. Bracken, E. E. Cleland, J. J. Elser, W. S. Harpole, J. T. Ngai, E. W. Seabloom, J. B. Shurin, and J. E. Smith. 2007. Consumer versus resource control of producer diversity depends on ecosystem type and producer community structure. Proceedings of the National Academy of Sciences USA 104:1090410909.

Howarth, R. W., et al. 1996. Regional nitrogen budgets and riverine N \& P fluxes for the drainages to the North Atlantic Ocean: natural and human influences. Biogeochemistry 35:75-139.

Huang, Y. J., et al. 2011. Airway microbiota and bronchial hyperresponsiveness in patients with suboptimally controlled asthma. Journal of Allergy and Clinical Immunology 127:372-381.

Johnson, L., et al. 2009. The influence of land use on stream biofilm nutrient limitation across eight North American ecoregions. Canadian Journal of Fisheries and Aquatic Sciences 66:1081-1094.

Kelly, J. R., and M. A. Harwell. 1990. Indicators of ecosystem recovery. Environmental Management 14:527-545.

Lewis, W. M., J. M. Melack, W. H. McDowell, M. McClain, and J. E. Richey. 1999. Nitrogen yields from undisturbed watersheds in the Americas. Biogeochemistry 46:149-162.

Marzolf, E. R., P. J. Mulholland, and A. D. Steinman. 1994. Improvements to the diurnal upstream-downstream dis- 
solved-oxygen change technique for determining wholestream metabolism in small streams. Canadian Journal of Fisheries and Aquatic Sciences 51:1591-1599.

McCormick, P. V., and J. Cairns. 1994. Algae as indicators of environmental change. Journal of Applied Phycology 6:509526.

McCune, B., and M. J. Mefford. 1999. PC-ORD: multivariate analysis of ecological data. Version 4 for Windows. MjM Software Design, Gleneden Beach, Oregon, USA.

Menetrey, N., L. Sager, B. Oertli, and J.-B. Lachavanne. 2005. Looking for metrics to assess the trophic state of ponds: macroinvertebrates and amphibians. Aquatic Conservation: Marine and Freshwater Ecosystems 15:653-664.

Niemi, G. J., and M. E. McDonald. 2004. Application of ecological indicators. Annual Review of Ecology, Evolution, and Systematics 35:89-111.

Odum, E. P. 1985. Trends expected in stressed ecosystems. BioScience 35:419-422.

Odum, H. T. 1956. Primary production in flowing waters. Limnology and Oceanography 1:102-117.

Pan, Y., R. J. Stevenson, B. H. Hill, A. T. Herlihy, and G. B. Collins. 1996. Using diatoms as indicators of ecological conditions in lotic systems: a regional assessment. Journal of the North American Benthological Society 15:481-495.

Potapova, M., and D. F. Charles. 2007. Diatom metrics for monitoring eutrophication in rivers of the United States. Ecological Indicators 7:48-70.

Pringle, C. M., and J. A. Bowers. 1984. An in situ substratum fertilization technique: diatom colonization on nutrientenriched, sand substrata. Canadian Journal of Fisheries and Aquatic Sciences 41:1247-1251.

Rapport, D. J., H. A. Regier, and T. C. Hutchinson. 1985. Ecosystem behavior under stress. American Naturalist 125:617-640.

Ryther, J. H., and W. M. Dunstan. 1971. Nitrogen, phosphorus, and eutrophication in the coastal marine environment. Science 171:1008-1013.

Schindler, D. W. 1990. Experimental perturbations of whole lakes as tests of hypotheses concerning ecosystem structure and function. Oikos 57:25-41.

Sickman, J. O., J. M. Melack, and J. L. Stoddard. 2002. Regional analysis of inorganic nitrogen yield and retention in high-elevation ecosystems of the Sierra Nevada and Rocky Mountains. Biogeochemistry 57:341-374.
Simberloff, D. 1998. Flagships, umbrellas, and keystones: Is single-species management passé in the landscape era? Biological Conservation 83:247-257.

Smith, V. H., and D. W. Schindler. 2009. Eutrophication science: Where do we go from here? Trends in Ecology and Evolution 24:201-207.

Smith, V. H., G. D. Tilman, and J. C. Nekola. 1999. Eutrophication: impacts of excess nutrient inputs on freshwater, marine, and terrestrial ecosystems. Environmental Pollution 100:179-196.

Steinman, A. D., and G. A. Lamberti. 1996. Biomass and pigments of benthic algae. Pages 295-313 in F. R. Hauer and G. A. Lamberti, editors. Methods in stream ecology. Academic Press, San Diego, California, USA.

Steneck, R. S., and M. N. Dethier. 1994. A functional group approach to the structure of algal-dominated communities. Oikos 69:476-498.

Storey, J. D., and R. Tibshirani. 2003. Statistical significance for genomewide studies. Proceedings of the National Academy of Sciences USA 100:9440.

Suding, K. N., S. L. Collins, L. Gough, C. Clark, E. E. Cleland, K. L. Gross, D. G. Milchunas, and S. Pennings. 2005. Functional- and abundance-based mechanisms explain diversity loss due to $\mathrm{N}$ fertilization. Proceedings of the National Academy of Sciences USA 102:4387-4392.

Tank, J. L., and W. K. Dodds. 2003. Nutrient limitation of epilithic and epixylic biofilms in ten North American streams. Freshwater Biology 48:1031-1049.

Vitousek, P. M., J. D. Aber, R. W. Howarth, G. E. Likens, P. A. Matson, D. W. Schindler, W. H. Schlesinger, and D. G. Tilman. 1997. Human alteration of the global nitrogen cycle: sources and consequences. Ecological Applications 7:737750 .

Waide, R. B., M. R. Willig, C. F. Steiner, G. Mittelbach, L. Gough, S. I. Dodson, G. P. Juday, and R. Parmenter. 1999. The relationship between productivity and species richness. Annual Review of Ecology and Systematics 30:257-300.

Welch, E. B., J. M. Jacoby, R. R. Horner, and M. R. Seeley. 1988. Nuisance biomass levels of periphytic algae in streams. Hydrobiologia 157:161-168.

Wetzel, R. G., and G. E. Likens. 2000. Limnological analyses. Springer-Verlag, New York, New York, USA.

\section{Supplemental Material}

Appendix A

Distribution of ambient nitrate concentrations and molar nitrate: orthophosphate ratios among streams used in this study, with photographs of the experimental design and measured nutrient diffusion rates (Ecological Archives A023-011-A1).

\section{Appendix B}

List of functional groupings to which algal species were assigned (Ecological Archives A023-011-A2).

\section{Appendix C}

Complete summary of general linear model results (Ecological Archives A023-011-A3).

\section{Appendix D}

Effects of physical and chemical covariates on ecosystem and community-level general linear model results (Ecological Archives A023-011-A4).

\section{Supplement}

Complete data set used in all analyses conducted in this manuscript, with corresponding metadata (Ecological Archives A023-011-S1). 